\title{
Modern Architecture and Climate
}

\author{
Brian Ford
}

Book Review / SUSTAINABILITY

\author{
Modern Architecture and Climate: \\ Design before Air Conditioning \\ By Daniel A. Barber \\ Princeton University Press, 2020 \\ 8 in. $\times 10.5$ in. [203 $\mathrm{mm} \times 267 \mathrm{~mm}$ ] \\ 76 color $+196 \mathrm{~b} / \mathrm{w}$ illustrations \\ 336 pages \\ $\$ 60.00 / £ 50.00$ (hardcover) \\ ISBN: 978-0-691-17003-9
}

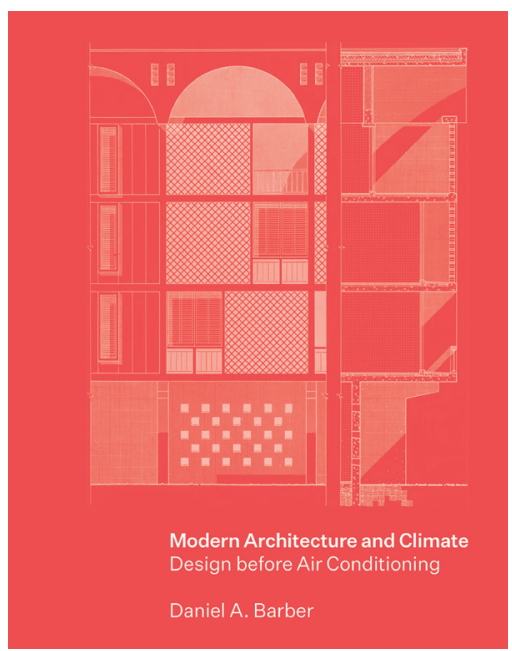

The introductory essay, "Architecture, Media and Climate" starts out by describing an unbuilt project by Le Corbusier of 1931; a three-story block of narrow-fronted, deep-plan apartments (the Barcelona Lotissements). Reference to the original plans, sections, models, and perspectives, reveal the importance of considerations of "light, air and the relationship to the sun." Daylight penetrates the deepest part of the plan via an open staircase, which also promotes ventilation across the plan to discharge above the roof. Large center-pivot louvers set within the façade at the first and second floor levels protect the glazing and enable the occupants to moderate the impact of diurnal and seasonal variations; active rather than 
passive recipients of the internal environment. The exposed intermediate concrete floors and party walls would have also contributed significantly to the stabilization of internal temperatures (had this project been built).

The choice of an unbuilt project to introduce a discussion of these concerns, given the large number of completed projects by Corbu around this time, seems curious. Do the immutable qualities of the unbuilt project hold more appeal than the messy realities of that which has been completed? Whatever the reason, Barber asserts that this project serves to set out a range of design ideas that "became a significant thread in architectural modernism over the next few decades." The importance of the operable shading louvers in particular, not only in preventing unwanted solar gain but in their formal expression, are presented as a defining character of early modernism, in an era prior to the widespread adoption of air conditioning. The significance of this, and its relevance to contemporary architectural practice and the huge challenges society now faces, are at the heart of this book. As the author says: "This book operates at the intersection of careful, theoretical elaboration of architectural-historical complexities and the urgency of the climate crisis."

Chapter 1 "Obstacles" refers primarily to the exclusivity of the formalist doctrines which dominated theoretical discourse and pedagogy (but not practice) from the 1960 s until relatively recently. This concern for formalism, and the production of novel forms and spaces, ignored concerns regarding climatic response and the social and economic context, which were regarded as threats to the "autonomy" of the architect. As Barber shows, this has impacted significantly on the interpretation of the work of Le Corbusier and other modernists, to the extent that the climatic considerations of their work has only rarely been referred to (although increasingly so in the last 20 years). He goes on to illustrate how concerns for climate and its moderation by means of building form and fabric, were central to many of Corbusier's buildings, although at the time, "Le Corbusier is atypical in taking on...the importance of climate as a conceptual driver for design." (p. 29)

Corbu's inventiveness in this field is well known; the development of the brise-soleil, the mur neutralisant and respiration exacte have been discussed by Banham, and others since, in great detail. What is less frequently reviewed are the processes involved in developing, testing, and refining these ideas in relation to specific projects. Corbu's diagrams showing the sun path in summer and winter were frequently attached to sketches of early proposals, and subsequently refined using detailed drawings of altitude and azimuth in relation to plan and section, and by the use of the "sun-rose" when testing models in the office. It is therefore a delight to see the paper Problemes de l'ensoleillement: le brise-soleil from 1946 reproduced in full. For those concerned with the process of embedding environmental design ideas within the broader architectural 
design process this is a real treasure. My only disappointment with this chapter was that Corbu's work in India which, it could be argued, represents his most mature response to climate, was not explored in more detail.

The discussion of the importance of shading in different climates is continued in Chapter 2 with its focus on Brazilian architecture in the 1940s and '50s. While the climatic context was seen to be challenging (how to prevent overheating), the social and political context (which favored modernism) was clearly significant in terms of the procurement of public and commercial buildings. Of particular interest are the comments of architects at the time regarding the process by which ideas on climate control, and shading in particular, were developed and tested. Milton Roberto indicated that the design of the shading for the IRB building in Rio (1936) involved a collaborative process with a climate consultant (Paulo $\mathrm{Sa}$ ), who researched the performance implications of different options, which resulted in different façade treatments according to their solar exposure. Barber suggests that the IRB building is "the first example of what the Olgyay brothers would later call 'bioclimatic' architecture ... built to maximise daylight without overheating and to manage internal conditioning without a mechanical cooling system."

Indeed, it is Paulo Sa's diagram of seasonal radiation patterns for Rio de Janeiro and the drawings of the sistema guilhotina window system which reveal the innovative thinking which underpinned the design of the different façades of the IRB building. Other projects are used to illustrate how widely this general approach was taken up in Brazil, with numerous photographs and drawings reproduced from articles in the architectural journals of the time, allowing a level of technical examination of the projects that is unusual for a book which will probably be located under "history \& theory" in the library. In this, Daniel Barber is doing academic colleagues, students, and practitioners a great service. Could this represent a reconciliation between the science and theory of architecture?

The third chapter, which concludes the first part of the book, pursues how ideas on climate and architecture were developing in parallel with work in Europe and Brazil by architects in the US, focusing initially on the work of Richard Neutra (in the US and Puerto Rico) and then more broadly on work by other US architects working abroad, often for the State Department, which was (in Barber's words) "experimenting with how modern architecture could frame and facilitate policy and economic initiatives." In Neutra's work in Puerto Rico it is interesting to note how his concerns seek to integrate a response to climate with a model of economic and social transformation (in contemporary parlance a "sustainable" approach) although this was certainly not consistent across his practice. It is apparent that many of the buildings constructed under the auspices of the State Department's Foreign Building Operations (FBO) in the 1950s used the language of shading 
without the detailed understanding of the sun path which underpinned buildings like the IRB in Rio. An exception to this was José Luis Sert's embassy, residence, and staff housing in Bagdad (1955-61), "clearly articulating the means of shading, screening and otherwise engaging the path of the sun." The photographs and drawings are a delight, and very much deserve the prominence given to them. In rounding out the first part of the book (the globalization of the International Style) Barber refers to an omission from his narrative; the discussion of the emergence of "Tropical Architecture," particularly through the work of Maxwell Fry and Jane Drew in Africa and India. This is "justified by the wealth of literature on the topic emergent in the last decade or so."

The second part of the book covers what Barber describes as "The American Acceleration"; how in the 1950s, '60s, and '70s, the growth in the US economy and its international economic and cultural reach, which dominated this era, impacted on architecture. Chapter 3 discusses how US architecture in the 1950s, and particularly housing, continued to be concerned with issues of climate, and the process of how to design in response to climate became a recurrent theme. Both professional journals like Architectural Forum, and in popular magazines like House Beautiful, which ran a very influential series (the Climate Control Project) from 1949-52, numerous articles focused on both the principles and practice of "designing with climate"; the implications of diurnal and seasonal variations, the use of orientation, shading, ventilation, and materials to enable comfort to be achieved without air conditioning. Popular interest in these issues chimed with the white middle-class migration to the suburbs in the 50 s and 60 s and reflects the fact that air conditioning in housing was still largely reserved for the very wealthy.

The role of Victor and Aladar Olgyay in defining an approach to climate sensitive design in the 1950 s and 60 s is described in Chapter 5 . As architects, they had successfully engaged in practice prior to undertaking research at MIT and Princeton; they also advised other architects and had significant international influence. They promoted a design approach focused on the occupant at its heart. This approach included the definition and testing of an environmental strategy based on an analysis of climate, the use of physical modeling (of sun path and daylighting), charts, and steady-state calculations of thermal performance. This was of course prior to the development of inexpensive and powerful computing, and although very influential in schools of architecture, it was widely regarded as too cumbersome by many in practice. The relevance of the Olgyays' work became relegated to the realm of "architectural science" research and teaching in universities, while practice (at the behest of commercial interests) became increasingly seduced by the opportunities of air conditioning and the sealed façade, made economically achievable by cheap fossil fuels. 
This latter development really took off in the 1960s, and is discussed by the author in the final chapter "Conditioning." Despite the excellent earlier work by many architects in responding to climate in different parts of the world (as described in earlier chapters), air conditioning became increasingly affordable and was being applied in part "to rectify errors or inadequacies in building." The developments in air conditioning came hand in hand with the development of the sealed glass façade, and the complexities of external shading (as applied in the '40s and '50s) were gradually abandoned. The fact that this resulted in a huge increase in energy consumption was of little concern as energy was cheap and the environmental consequences were of little concern to those procuring commercial office buildings.

Throughout the book's early chapters, Barber describes how the US used the image of modern architecture to promote the US both culturally and economically around the world. Nevertheless, in the last chapter Barber chooses to focus on his "careful, theoretical elaboration of architecturalhistorical complexities" which, in my view, leads to over-elaboration and the risk of obfuscation. Passing reference is made in the book to the finite nature of fossil fuels and the "limits to growth," but the birth and growth of "environmentalism" in the 1960 s receives scant attention. However, warnings regarding the impact of the built environment on the natural environment were provided by many scientists in different fields and given an international platform at the first UN Conference on the Environment in Stockholm in 1972. The global impact of man on the environment was already apparent and annual increases in global carbon emissions had been measured since 1958. By 1972 alarm bells were ringing, but few politicians understood the implications of ocean acidification and global warming, and the fossil fuel industries actively undermined the emerging climate science. In the intervening 50 years, little has been done to address these concerns. For many it has been easier to turn a blind eye in order to maintain "business as usual."

Daniel Barber's historical narrative is fascinating and holds many useful lessons for a contemporary audience. But time is short. I wonder if the next generation of architects, who are currently organizing the Architects Climate Action Network, demanding changes to the architecture curriculum and greater engagement and action by practice, will have the patience to engage with Professor Barber's narrative and find the many treasures within. I hope so. 
Brian Ford, RIBA, FRSA, is an Emeritus Professor of Architecture at the University of Nottingham UK. Prior to this he was Head of the School of the Built Environment at the same university from 2003-2008. Ford is an architect and environmental design consultant with over 25 years' experience in professional practice. He led a series of research projects funded by the European Commission which focused on natural ventilation and passive cooling. E-mail: brian@naturalcooling.co.uk 